\title{
Sorting living mesenchymal stem cells using a TWIST1 RNA-based probe depends on incubation time and uptake capacity
}

\author{
Chantal Voskamp · Jeroen van de Peppel · Simona Gasparini • \\ Paolo Giannoni · Johannes P. T. M. van Leeuwen • Gerjo J. V. M. van Osch • \\ Roberto Narcisi
}

Received: 24 July 2019/Accepted: 7 November 2019/Published online: 14 November 2019

(C) The Author(s) 2019

\begin{abstract}
Bone marrow derived mesenchymal stromal cells (BMSCs) are multipotent progenitors of particular interest for cell-based tissue engineering therapies. However, one disadvantage that limit their clinical use is their heterogeneity. In the last decades a great effort was made to select BMSC subpopulations based on cell surface markers, however there is still no general consensus on which markers to use to obtain the best BMSCs for tissue regeneration. Looking for alternatives we decided to focus on a probe-based method to detect intracellular mRNA in living cells,
\end{abstract}

Electronic supplementary material The online version of this article (https://doi.org/10.1007/s10616-019-00355-w) contains supplementary material, which is available to authorized users.

C. Voskamp · S. Gasparini · G. J. V. M. van Osch .

R. Narcisi ( $\square)$

Department of Orthopaedics, Erasmus MC,

3015 CN Rotterdam, The Netherlands

e-mail: r.narcisi@erasmusmc.nl

J. van de Peppel · J. P. T. M. van Leeuwen

Department of Internal Medicine, Erasmus MC,

Rotterdam, The Netherlands

S. Gasparini · P. Giannoni

Department of Experimental Medicine, University of

Genova, Genoa, Italy

G. J. V. M. van Osch

Department of Otorhinolaryngology, Erasmus MC,

3015 CN Rotterdam, The Netherlands the SmartFlare technology. This technology does not require fixation of the cells and allows us to sort living cells based on gene expression into functionally different populations. However, since the technology is available it is debated whether the probes specifically recognize their target mRNAs. We validated the TWIST1 probe and demonstrated that it specifically recognizes TWIST1 in BMSCs. However, differences in probe concentration, incubation time and cellular uptake can strongly influence signal specificity. In addition we found that TWISTI ${ }^{\text {high }}$ expressing cells have an increased expansion rate compared to TWISTI $^{\text {low }}$ expressing cells derivedfrom the same initial population of BMSCs. The SmartFlare probes recognize their target gene, however for each probe and cell type validation of the protocol is necessary.

Keywords Mesenchymal stem cells (MSCs) · TWIST1 · RNA probes · Tissue engineering · Cell sorting $\cdot$ Expansion

\section{Introduction}

Multipotent progenitor cells from bone marrow aspirates can differentiate into chondrocytes, osteoblasts and adipocytes (Pittenger et al. 1999). These progenitor cells, often referred to as bone marrow-derived mesenchymal stem or stromal cells (BMSCs), are 
appealing for cell-based tissue engineering purposes. Unfortunately, their limited expansion capacity and their heterogeneity, hinder their clinical use (Banfi et al. 2000; Bonab et al. 2006; Chen et al. 2005; Li et al. 2011). Several studies investigated cell surface molecules to identify specific subpopulations of BMSCs (Alvarez-Viejo et al. 2015; Buhring et al. 2007; Cleary et al. 2016; Delorme et al. 2008; Sacchetti et al. 2007; Sivasubramaniyan et al. 2013). However, despite the great effort, there is still no general consensus on the surface markers that need to be used to define or select the best BMSC subset for tissue engineering. One drawback of surface markers is that their function is often unknown, so alternative markers are necessary to select cells according to their function (Clevers and Watt 2018).

Recently, a probe-based method to detect intracellular mRNA in living single cells has been developed, the SmartFlare technology (Seferos et al. 2007; Prigodich et al. 2009). The SmartFlare technique is a promising tool to sort BMSCs into functionally different populations. The SmartFlare probes are taken up by the cells via endocytosis and if the target mRNA is present, the probes bind to the target mRNA and fluorescent reporters are released and detectable (Figure S1A). Since the SmartFlare technology is available, this technique already successfully identified cancer cells (McClellan et al. 2015; Kronig et al. 2015) and pluripotent stem cells (Lahm et al. 2015). Additionally it was applied to investigate a Nodal expressing subpopulation of melanoma cells (Seftor et al. 2014), and to study a subpopulation of human BMSCs with an enhanced osteogenic potential (Li et al. 2016). However, other studies did not find a correlation between the SmartFlare fluorescence intensity and mRNA expression measured by RTPCR (Czarnek and Bereta 2017; Yang et al. 2018). In addition, Czarnek et al. (2017) found that the SmartFlare signal intensity correlates with the probe uptake ability of the cells.

To assess if the SmartFlare technique can be used to sort different populations of BMSCs based on gene expression, we focused on the validation of a probe for TWIST1. TWIST1 is a transcription factor that is involved in the regulation of BMSC proliferation (Goodnough et al. 2012; Isenmann et al. 2009; Tian et al. 2015) and differentiation (Isenmann et al. 2009; Boregowda et al. 2016; Cleary et al. 2017; Narcisi et al. 2015, 2016). In the present study, we evaluated the SmartFlare protocol in order to detect a specific probe signal in our culture conditions and illustrated that the SmartFlare fluorescence intensity is associated with probe concentration, incubation time and cellular uptake capacity.

\section{Materials and methods}

Isolation and culture of human adult bone marrow mesenchymal stem cells

Human adult bone marrow aspirates were obtained from femoral biopsies of 8 patients (22-79 years) undergoing total hip replacement (MEC 2015-644, MEC 2004-142: Erasmus Medical Center, Rotterdam; MEC 2011.07 Albert Schweitzer Hospital, Dordrecht), after obtaining informed consent and full ethical approval by the Erasmus MC and Albert Schweitzer ethics committee.

Human BMSCs were isolated, seeded at the density of 2300 cells $/ \mathrm{cm}^{2}$ and cultured as previously described in standard expansion media, containing 10\% FCS (Lonza, Verviers, Belgium; selected batch:1S016) and $1 \mathrm{ng} / \mathrm{ml}$ FGF2 (AbD Serotech, Kidlington, United Kingdom) (Narcisi et al. 2016). The medium was refreshed twice a week. BMSCs expanded for 3 to 6 passages were used for experiments.

\section{SmartFlare probes}

Cells were treated with the SmartFlare probe when they were sub-confluent. SmartFlare probes TWIST1Cy3 (the only label available for TWIST1), UptakeCy5, and GAPDH-Cy5 were purchased from Merck. The probes were resuspended in $50 \mu 1$ sterile nuclease free water, 1:20 prediluted in PBS (Lonza) and added to the cells with a final concentration of $50 \mathrm{pM}$ or $100 \mathrm{pM}$. The cells were incubated for 6 or $16 \mathrm{~h}$ at $37{ }^{\circ} \mathrm{C}$ and $5 \% \mathrm{CO}_{2}$ and analyzed using flow cytometry. To assure a broad range of TWIST1 gene expression during the validation of the TWIST1-Cy3 probe, BMSCs from two different donors were mixed and treated with the TWIST1-Cy3 probe.

Flow cytometry and FACS

Flow cytometry analysis was performed using a BD Fortessa and the data was analyzed using FlowJo V10 
software. The cells were sorted using a BD Biosciences FACS Aria and the data was analyzed using BD FACS Diva 8.0.1 software. Cell debris were excluded from the population through forward scatter (FSC)/side scatter (SSC) gate and doublets were excluded using FSC-A/FSC-H gate (Figure S2A). To confirm effective sorting, the sorted populations were reanalyzed (Figure S2B). Mean fluorescent intensity (MFI) was measured using FlowJo V10 software. The two different gates TWISTI ${ }^{\text {high }}$ and TWIST ${ }^{\text {low }}$ were established based on the TWIST1-Cy3 fluorescence intensity, 15-25\% of the extremes or two different gates TWIST1/Uptake ${ }^{\text {high }}$ and TWIST1/Uptake ${ }^{\text {low }}$ were established based on the TWIST1-Cy3 fluorescence intensity, $15 \%$ of the extremes with a comparable Uptake-Cy5 fluorescence intensity. The sorted cells were collected in PBS with 1\% FCS and reseeded with a density of 2300 cells per $\mathrm{cm}^{2}$ or used for RNA isolation.

Real time PCR analysis

Post-sorting, 200,000 BMSCs per sample were spun down and treated on ice with RLT lysis buffer (Qiagen, Hilden, Germany) with $1 \% \quad \beta$-mercaptoethanol. BMSCs in monolayer were washed with PBS and treated on ice with RLT lysis buffer (Qiagen) with $1 \% \beta$-mercaptoethanol. A range of $0.25-1.00 \mu \mathrm{g}$ of purified RNA (RNeasy Micro Kit; Qiagen) was reverse transcribed into cDNA (RevertAid First Strand cDNA Synthesis Kit; MBI Fermentas, St. Leon-Rot, Germany). RT-PCR was performed using an annealing temperature of $60{ }^{\circ} \mathrm{C}$ on a $\mathrm{C} 1000 \mathrm{Touch}^{\mathrm{TM}}$ Thermal Cycler using SybrGreen (Eurogentec, Seraing, Belgium). The data were normalized to the housekeeper gene RSP27a. The relative expression was calculated according to the $2^{-\Delta \Delta \mathrm{Ct}}$ formula. The primers used for RT-PCR are listed in (Table S1).

Data analysis

Linear correlation (Fig. 2c) was analyzed with GraphPad Prism Software 5.00 assuming normal distribution of the data.

\section{Results}

TWIST1 SmartFlare detects TWIST1 mRNA after $6 \mathrm{~h}$ using a concentration of $50 \mathrm{pM}$ in human BMSCs

SmartFlare probes enter the cell via endocytosis and this process can vary between different cell types (Choi et al. 2013). The probe incubation time and concentration which is suggested by the manufacturer is $16 \mathrm{~h}$ and $100 \mathrm{pM}$. However we also included a $6 \mathrm{~h}$ timepoint and a concentration of $50 \mathrm{pM}$ in order to verify whether or not it was possible to further optimize the SmartFlare protocol for TWIST1 in BMSCs. Interestingly, already after $6 \mathrm{~h}$ with a probe concentration of $50 \mathrm{pM}, 98.5 \%$ of the cells were positive for TWIST1 SmartFlare signal (Fig. 1a; lowest panel). No major differences in SmartFlare signal intensity were observed between the different probe concentrations and incubation times (Fig. 1a).

To study TWIST1-Cy3 signal specificity, BMSCs were treated with TWIST1-Cy3 probe for $16 \mathrm{~h}$ or $6 \mathrm{~h}$, sorted based on the TWIST1-Cy3 signal by FACS and subsequently tested by RT-PCR. Our FACS gating strategy consisted of sorting $15 \%$ of the BMSCs with the lowest TWIST1-Cy3 signal and $15 \%$ of the BMSCs with the highest TWIST1-Cy3 signal (TWIST1 ${ }^{\text {low }}$ vs TWIST1 ${ }^{\text {high }}$; Fig. 1b). To our surprise no difference in relative TWIST1 gene expression was detected between TWISTI ${ }^{\text {low }}$ and TWIST1 ${ }^{\text {high }}$ cells after $16 \mathrm{~h}$ of probe incubation (Fig. 1c). This indicates that although we observe a TWIST1 SmartFlare signal after $16 \mathrm{~h}$, this signal is probably not specific for TWIST1 gene expression. However after $6 \mathrm{~h}$ incubation we confirmed that TWISTI ${ }^{\text {high }}$ BMSCs have a higher TWIST1 gene expression than the TWIST1 low population (6.25-fold difference; Fig. 1c). These data shows that the TWIST1 probe specifically detects TWIST1 gene expression in this population of BMSCs already after $6 \mathrm{~h}$ incubation with a concentration of $50 \mathrm{pM}$ probe. In addition we observed that more than $97.3 \%$ of cells were positive for the Uptake control probe, a probe which is always fluorescent without binding to a target (Supplementary Figure 1B), with $50 \mathrm{pM}$ after $6 \mathrm{~h}$ of incubation.

To further determine the signal specificity of the TWIST1 probe after $6 \mathrm{~h}$, we analyzed the correlation between the TWIST1-Cy3 signal intensity and TWIST1 expression by RT-PCR. TWIST1 probe 
Fig. 1 TWIST1 SmartFlare probes are efficiently taken up by BMSCs after $6 \mathrm{~h}$. a Flow cytometry histogram of untreated BMSCs and BMSCs with $100 \mathrm{pM}$ or 50 pM TWIST1-Cy3 probe incubated for 16 or $6 \mathrm{~h}$, \% shows percentage $\mathrm{Cy} 5$ positive cells. b Gating strategy based on TWIST1Cy3 intensity. The doted graph represents unstained BMSCs and the gray graph represents BMSCs with TWIST1-Cy3 probes. c BMSCs were sorted based on TWIST1-Cy3 intensity after 16 and $6 \mathrm{~h}$ of probe incubation. TWIST1 transcripts were analysis by RT-PCR. Values represent the mean \pm SD from duplicates or quadruplicate

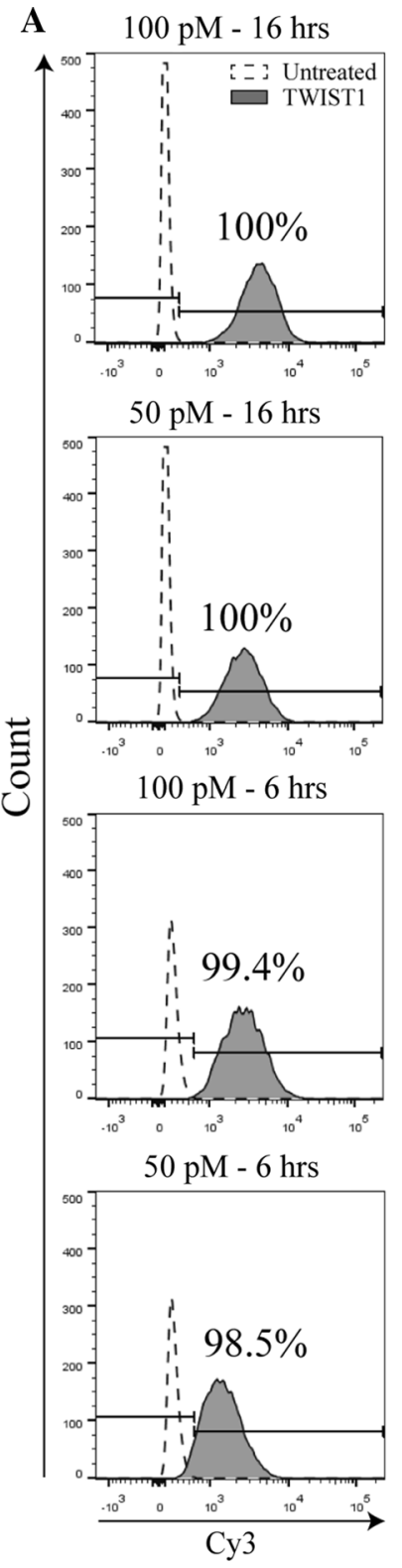

B

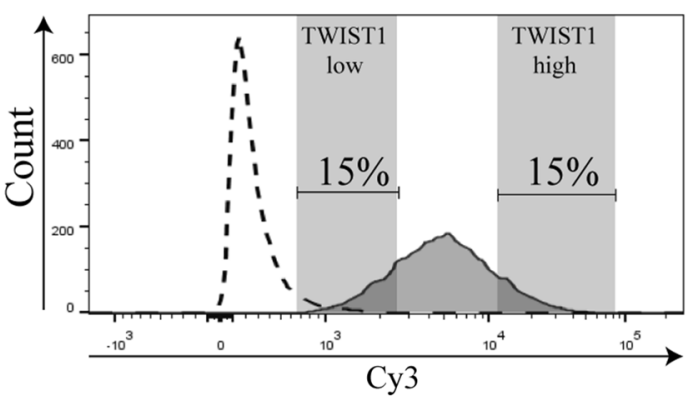

C
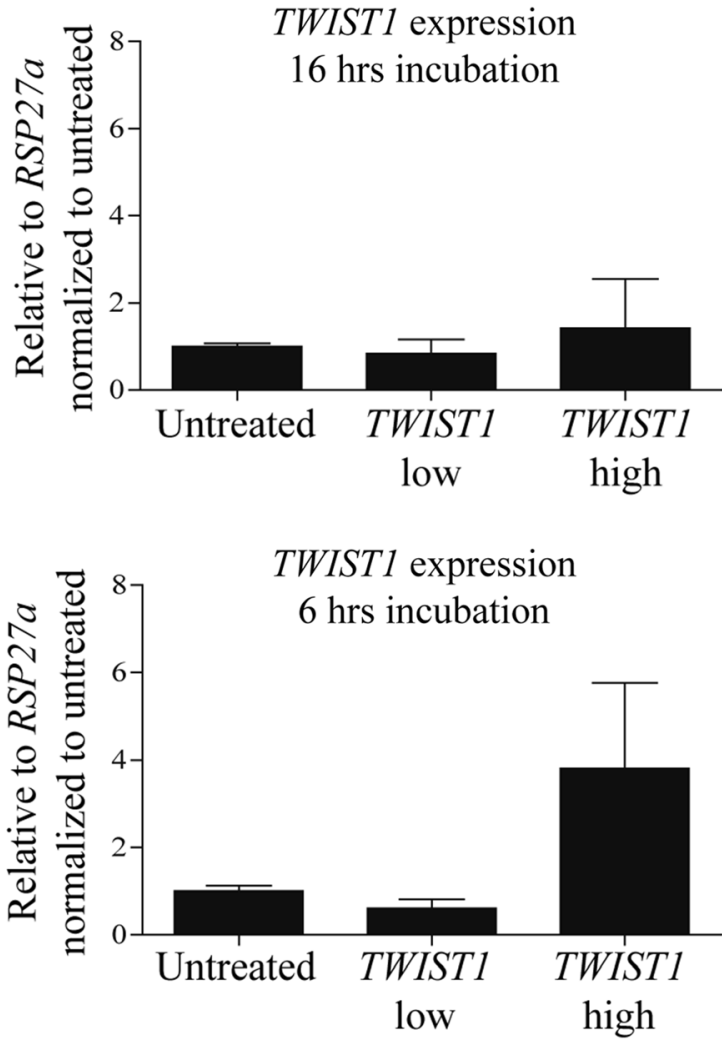

signal intensity from two BMSC populations (referred to as donor 1 and donor 2) was measured using flow cytometry, showing a higher intensity in donor 2 (8775 vs 5645 MFI; Fig. 2a). Transcript analysis confirmed the difference in TWISTI expression between the two donors, showing a higher expression in donor 2 (Fig. 2b). We therefore repeated the analysis in four other donors showing a positive and consistent correlation between TWIST1-Cy3 probe intensity and TWIST1 gene expression $\left(\mathrm{r}^{2}=0.997\right.$; Fig. $\left.2 \mathrm{c}\right)$. These data again confirms that the TWIST1 probe specifically targets the TWIST1 mRNA after $6 \mathrm{~h}$ of incubation.

Correction for cellular probe uptake improves TWISTl gene detection

When we repeated the sorting experiment with other donors not always differences in TWIST1 expression by RT-PCR were observed between TWISTI ${ }^{\text {low }}$ and TWIST ${ }^{\text {high }}$ sorted cells (Figure S4). Given that, and considering that Czarnek et al. recently showed that 


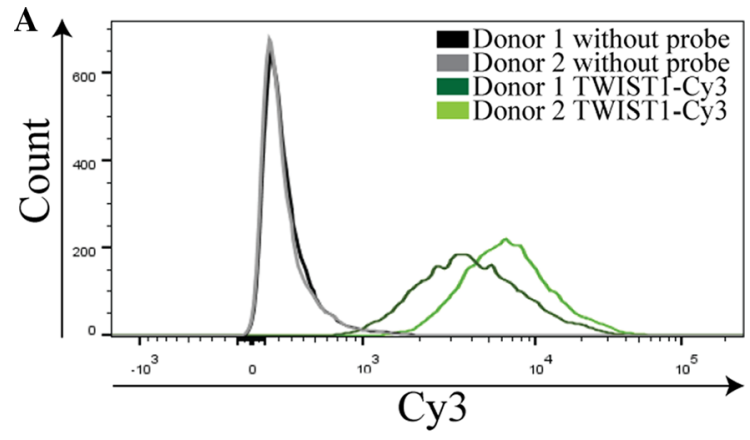

B

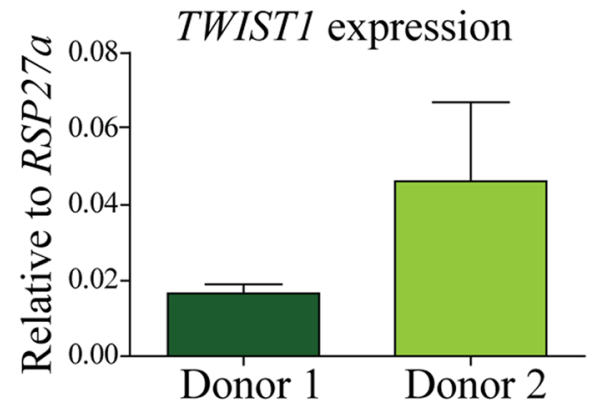

C

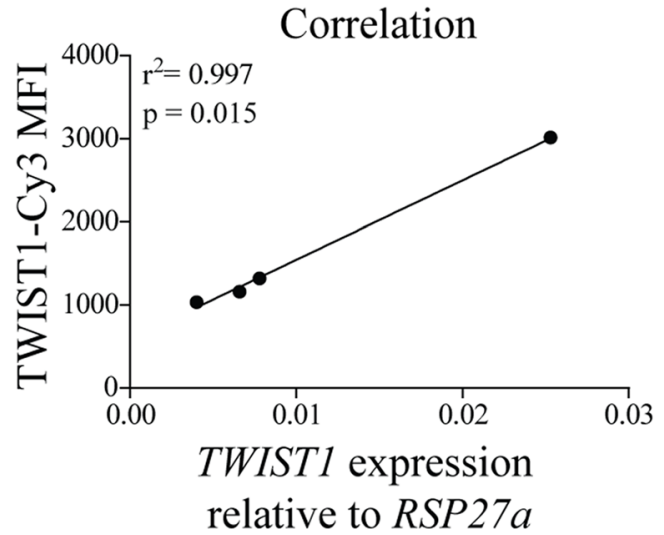

Fig. 2 TWIST1 SmartFlare detects TWIST1 mRNA expression. a Flow cytometry histogram of BMSCs from two donors untreated or treated with the TWIST1-Cy3 probe for $6 \mathrm{~h}$. b TWIST1 RT-PCR results, values represent the mean \pm SD from triplicates. c Correlation between TWIST1 expression measured by RT-PCR and TWIST1-Cy3 MFI. Dots represent different donors $(\mathrm{N}=4)$

uptake capacity can influence the SmartFlare signal specificity (Czarnek and Bereta 2017), we decided to carefully monitor uptake in our BMSC populations.

To evaluate the effect of cellular uptake on the TWIST1 signal, BMSCs from 4 different donors were double labeled with TWIST1-Cy3 and Uptake-Cy5 probes (Figure S1B). At least $65 \%$ of the BMSCs were able to take up both the TWIST1-Cy3 and Uptake-Cy5 probe (Fig. 3a) and we demonstrated that BMSCs from different donors have a different uptake capacity (Figure S5). Moreover, it is clear from the FACS analysis that there is a general positive correlation between Uptake-Cy5 signal and TWIST-Cy3 signal (the higher the TWIST1 signal, the higher the Uptake signal), although with variation between donors (Fig. 3b and Figure S5). This indicates that in BMSCs from different donors the TWIST1-Cy3 signal can be affected by the cellular uptake capacity, with a degree that depends on the individual uptake capacity of the cells in the BMSC population. To determine whether or not the detected differences in cellular uptake have an effect on TWIST1 gene detection, BMSCs with a high variation in Uptake-Cy5 fluorescence intensity were treated with both TWIST1-Cy3 and Uptake-Cy5 probes and were sorted by FACS using two different sorting strategies or left unsorted. In the first gating strategy, similar to that previously used, $15 \%$ of the BMSCs with the lowest TWIST1-Cy3 signal and 15\% of the BMSCs with the highest TWIST1-Cy3 signal $\left(\right.$ TWISTI ${ }^{\text {high }}$ ) were sorted (Fig. 3c; left panel). In the second gating strategy we corrected for the uptake signal (Fig. 3d; left panel) by sorting TWISTI $1^{\text {high }}$ and TWISTI $^{\text {low }}$ cells with a minimal uptake variation. Gene expression analysis showed no differences between TWISTI ${ }^{\text {low }}$ and TWIST ${ }^{\text {high }}$ populations in the absence of uptake correction (Fig. 3c; left middle panel), while a strong difference (13.3-fold) was detected between the subpopulations where the TWIST1 signal was corrected for the uptake (Fig. 3d; left middle panel). These data indicate that differences in cellular uptake can strongly influence TWISTI detection using SmartFlare. In addition, we observed that the sorted populations of BMSCs corrected for cellular uptake had a similar cellular granularity (Fig. 3c, d; right middle panel) and cell size (Fig. 3c, $\mathrm{d}$; right panel) compared to the populations sorted without uptake correction.

TWIST ${ }^{\text {high }}$ BMSCs have a high expansion capacity

In order to further validate our sorting strategy and prove for the first time the pro-proliferative role of TWIST1 in a subpopulation of BMSCs, we sorted TWISTI ${ }^{\text {high }}$ and TWISTI ${ }^{\text {low }}$ cells and we compared their expansion capacity post-sorting. RT-PCR confirmed that $T W I S T 1^{\text {high }}$ BMSCs had a higher relative 
Fig. 3 Correction for cellular probe uptake improves TWIST1 gene detection. a Flow cytometry plots of BMSCs of four donors treated with both TWIST1-Cy3 and UptakeCy5 probe for $6 \mathrm{~h}$ (grey). The perpendicular lines represent the unstained control (black) for each donor. \% shows percentage Cy3 and Cy5 double positive cells. b, c FACS gating strategies using TWIST1-Cy3 and UptakeCy5 probes for $6 \mathrm{~h}$ and TWIST1 RT-PCR results, values represent the mean \pm SD from duplicates. SSC-A MFI and FSC MFI of Standard and Uptake correction low vs high
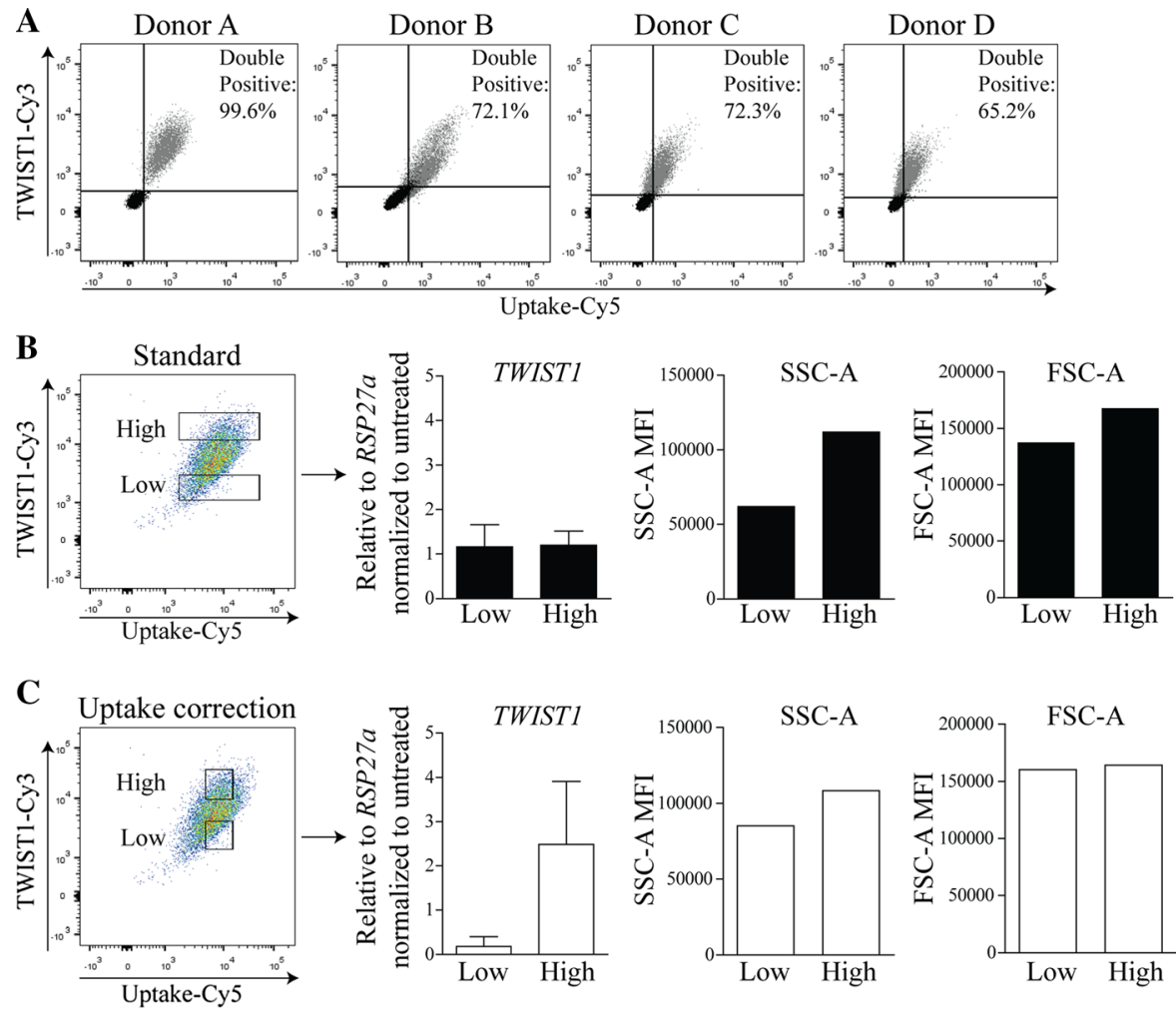

TWIST1 gene expression than TWIST1 ${ }^{\text {low }}$ BMSCs (1.6-fold difference; Fig. 4a). No evident differences in morphology between TWIST1 ${ }^{\text {low }}$ and TWIST ${ }^{\text {high }}$ were observed 5 days post sorting, while 16 days post sorting TWIST1 ${ }^{\text {low }}$ BMSCs appeared more enlarged compared to the TWIST1 ${ }^{\text {high }}$ BMSCs (Fig. 4b). Moreover, TWIST1 ${ }^{\text {high }}$ BMSCs showed a higher expansion capacity than the TWISTI ${ }^{\text {low }}$ population (Fig. 4c; 1.5 -
Fig. 4 TWISTI ${ }^{\text {high }}$ BMSCs have a high proliferation capacity. a TWIST1 RTPCR results of Untreated, TWIST $^{\text {low }}$ and TWIST1 $1^{\text {high }}$ populations, values represent the mean $\pm \mathrm{SD}$ from duplicates.

b Morphology of BMSCs 5 days and 16 days after being sorted. Scale bar represents $100 \mu \mathrm{m}$. c Cell numbers relative to $\mathrm{t}=0$ of Untreated, TWISTI ${ }^{\text {low }}$ and TWIST $1^{\text {high }}$ were passaged and counted on day 0 , day 5 , day 10 and day 16
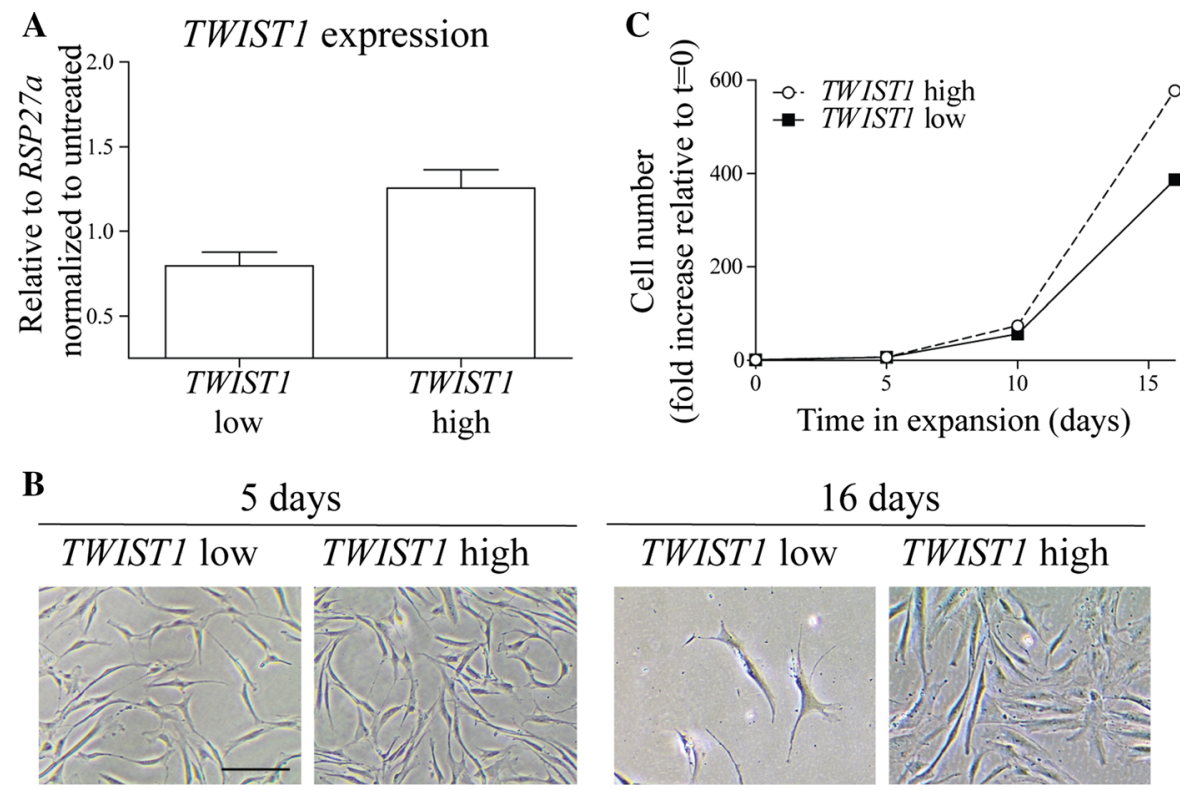
fold difference after 3 passages) and, 16 days post sorting, the TWIST1 ${ }^{\text {low }}$ BMSCs stop growing while the TWISTI ${ }^{\text {high }}$ BMSCs were still expanding (data not shown). This indicates that within a population of BMSCs derived from one donor, the TWIST $1^{\text {high }}$ expressing cells have a higher expansion rate compared to the TWIST1 $1^{\text {low }}$ expressing cells.

\section{Discussion}

In this study, we evaluated the use of the SmartFlare technique to detect TWISTI expression at a single cell level in living BMSCs. Multiple studies successfully detected mRNA expression with the SmartFlare technique (McClellan et al. 2015; Kronig et al. 2015; Lahm et al. 2015; Seftor et al. 2014; Li et al. 2016). However, two recent studies showed that different SmartFlare probes were not able to specifically detect their target mRNAs in cell lines and monocytes (Czarnek and Bereta 2017; Yang et al. 2018). Here we showed that SmartFlare is an effective tool to detect TWIST1 gene expression in living BMSCs, but differences in probe concentration, incubation time and cellular uptake can influence the SmartFlare sensitivity and possibly lead to misinterpretation of the results.

We observed that specific detection of TWIST1 mRNA expression in BMSCs is possible already after $6 \mathrm{~h}$ of incubation with a concentration of $50 \mathrm{pM}$, TWIST1-Cy3 probe. While most of the studies used 16 h (McClellan et al. 2015; Seftor et al. 2014; Li et al. 2016; Czarnek and Bereta 2017) or even a longer incubation time (Kronig et al. 2015; Lahm et al. 2015; Czarnek and Bereta 2017), we were not able to specifically detect TWIST1 after $16 \mathrm{~h}$ incubation (Figure S4). The SmartFlare technology was recently applied in BMSCs (Li et al. 2016), but never for the detection of TWIST1 expression. In our study a different protocol was needed compared to the RUNX2 and the SOX9 probes used by Li et al. (2016). Possible explanations could be ascribed to differences in culture conditions, origin of BMSCs or binding efficiency of the probe to the target.

In addition, our data indicate that BMSCs can have a high difference in probe uptake. We observed that these differences strongly influence the TWIST1 SmartFlare specificity. This confirms confirms the data previously reported where was shown that
SmartFlare intensity was affected by cellular uptake in 293T cells (Czarnek and Bereta 2017). The differences in uptake capacity can be explained by differences in cell cycle stage between the BMSCs, since endocytosis is reduced during mitosis (Fielding et al. 2012). Here, we were able to overcome this problem by correcting TWIST1 detection for the cellular uptake based on Uptake probe intensity during sorting. Next, we demonstrate that TWIST1 $1^{\text {high }}$ expressing BMSCs have a higher expansion capacity than TWIST1 ${ }^{\text {low }}$ expressing BMSCs derived from the same donor. A population of BMSCs with a high TWIST1 expression and a high proliferation rate have already been reported by us and others (Isenmann et al. 2009; Cleary et al. 2017; Narcisi et al. 2015). Here, we showed for the first time that within the same population of BMSCs, the subpopulation of TWIST $1^{\text {high }}$ expressing cells have a higher expansion capacity than the TWISTI ${ }^{\text {low }}$ expressing cells. Alternatively to the use of the uptake control, in a previous report the ratio between two functional markers, RUNX2 and SOX9, was applied (Li et al. 2016). This indirect method could also be used, since it would automatically take into account differences in uptake, as these would not change the ratio, but only the intensity of the individual signals.

\section{Conclusion}

In summary, our data indicate that for each probe and cell type, a validation of the SmartFlare protocol is necessary. Giving that, we were able to successfully use the TWIST1 probe to detect TWIST1 mRNA in living BMSCs and to sort TWIST1 ${ }^{\text {high }}$ BMSCs from a heterogeneous population of cells. Overall, we showed that SmartFlare is a promising tool to divide a heterogeneous population of cells based on gene expression in functionally different populations.

Acknowledgements J.L.M. Koevoet, A.L.M. Vriends, T.W. Kan, P. van Geel, G. Kremers are acknowledged for technical assistance. We are thankful to the Erasmus MC FACS sorting facility for support with FACS machines This work was financially supported by the Dutch Arthritis Foundation (ReumaNederland; 16-1-201), and R.N. was further supported by a Veni grant from NWO (13659). 


\section{Compliance with ethical standards}

Conflict of interest The authors declare no competing interests.

Ethics approval and consent to participate Human adult bone marrow aspirates were obtaine after obtaining informed consent and full ethical approval by the Erasmus MC and Albert Schweitzer ethics committee.

Open Access This article is distributed under the terms of the Creative Commons Attribution 4.0 International License (http:// creativecommons.org/licenses/by/4.0/), which permits unrestricted use, distribution, and reproduction in any medium, provided you give appropriate credit to the original author(s) and the source, provide a link to the Creative Commons license, and indicate if changes were made.

\section{References}

Alvarez-Viejo M, Menendez-Menendez Y, Otero-Hernandez J (2015) CD271 as a marker to identify mesenchymal stem cells from diverse sources before culture. World J Stem Cells 7:470

Banfi A, Muraglia A, Dozin B, Mastrogiacomo M, Cancedda R, Quarto R (2000) Proliferation kinetics and differentiation potential of ex vivo expanded human bone marrow stromal cells: implications for their use in cell therapy. Exp Hematol 28:707

Bonab MM, Alimoghaddam K, Talebian F, Ghaffari SH, Ghavamzadeh A, Nikbin B (2006) Aging of mesenchymal stem cell in vitro. BMC Cell Biol 7:14

Boregowda SV, Krishnappa V, Haga CL, Ortiz LA, Phinney DG (2016) A clinical indications prediction scale based on TWIST1 for human mesenchymal stem cells. EBioMedicine 4:62

Buhring HJ, Battula VL, Treml S, Schewe B, Kanz L, Vogel W (2007) Novel markers for the prospective isolation of human MSC. Ann N Y Acad Sci 1106:262

Chen J, Sotome S, Wang J, Orii H, Uemura T, Shinomiya K (2005) Correlation of in vivo bone formation capability and in vitro differentiation of human bone marrow stromal cells. J Med Dent Sci 52:27

Choi CH, Hao L, Narayan SP, Auyeung E, Mirkin CA (2013) Mechanism for the endocytosis of spherical nucleic acid nanoparticle conjugates. Proc Natl Acad Sci U S A 110:7625

Cleary MA, Narcisi R, Focke K, van der Linden R, Brama PA, van Osch GJ (2016) Expression of CD105 on expanded mesenchymal stem cells does not predict their chondrogenic potential. Osteoarthr Cartil 24:868

Cleary MA, Narcisi R, Albiero A, Jenner F, de Kroon LMG, Koevoet W, Brama PAJ, van Osch G (2017) Dynamic regulation of TWIST1 expression during chondrogenic differentiation of human bone marrow-derived mesenchymal stem cells. Stem Cells Dev 26:751
Clevers H, Watt FM (2018) Defining adult stem cells by function, not by phenotype. Annu Rev Biochem 87:1015

Czarnek M, Bereta J (2017) SmartFlares fail to reflect their target transcripts levels. Sci Rep 7:11682

Delorme B, Ringe J, Gallay N, Le Vern Y, Kerboeuf D, Jorgensen C, Rosset P, Sensebe L, Layrolle P, Haupl T, Charbord P (2008) Specific plasma membrane protein phenotype of culture-amplified and native human bone marrow mesenchymal stem cells. Blood 111:2631

Fielding AB, Willox AK, Okeke E, Royle SJ (2012) Clathrinmediated endocytosis is inhibited during mitosis. Proc Natl Acad Sci U S A 109:6572

Goodnough LH, Chang AT, Treloar C, Yang J, Scacheri PC, Atit RP (2012) Twist1 mediates repression of chondrogenesis by beta-catenin to promote cranial bone progenitor specification. Development 139:4428

Isenmann S, Arthur A, Zannettino AC, Turner JL, Shi S, Glackin CA, Gronthos S (2009) TWIST family of basic helix-loophelix transcription factors mediate human mesenchymal stem cell growth and commitment. Stem Cells 27:2457

Kronig M, Walter M, Drendel V, Werner M, Jilg CA, Richter AS, Backofen R, McGarry D, Follo M, Schultze-Seemann W, Schule R (2015) Cell type specific gene expression analysis of prostate needle biopsies resolves tumor tissue heterogeneity. Oncotarget 6:1302

Lahm H, Doppler S, Dressen M, Werner A, Adamczyk K, Schrambke D, Brade T, Laugwitz KL, Deutsch MA, Schiemann M, Lange R, Moretti A, Krane M (2015) Live fluorescent RNA-based detection of pluripotency gene expression in embryonic and induced pluripotent stem cells of different species. Stem Cells 33:392

Li Z, Liu C, Xie Z, Song P, Zhao RC, Guo L, Liu Z, Wu Y (2011) Epigenetic dysregulation in mesenchymal stem cell aging and spontaneous differentiation. PLoS ONE 6:e20526

Li B, Menzel U, Loebel C, Schmal H, Alini M, Stoddart MJ (2016) Monitoring live human mesenchymal stromal cell differentiation and subsequent selection using fluorescent RNA-based probes. Sci Rep 6:26014

McClellan S, Slamecka J, Howze P, Thompson L, Finan M, Rocconi R, Owen L (2015) mRNA detection in living cells: a next generation cancer stem cell identification technique. Methods 82:47

Narcisi R, Cleary MA, Brama PA, Hoogduijn MJ, Tuysuz N, ten Berge D, van Osch GJ (2015) Long-term expansion, enhanced chondrogenic potential, and suppression of endochondral ossification of adult human MSCs via WNT signaling modulation. Stem Cell Rep 4:459

Narcisi R, Arikan OH, Lehmann J, Ten Berge D, van Osch GJ (2016) Differential effects of small molecule WNT Agonists on the multilineage differentiation capacity of human mesenchymal stem cells. Tissue Eng Part A 22:1264

Pittenger MF, Mackay AM, Beck SC, Jaiswal RK, Douglas R, Mosca JD, Moorman MA, Simonetti DW, Craig S, Marshak DR (1999) Multilineage potential of adult human mesenchymal stem cells. Science 284:143

Prigodich AE, Seferos DS, Massich MD, Giljohann DA, Lane BC, Mirkin CA (2009) Nano-flares for mRNA regulation and detection. ACS Nano 3:2147

Sacchetti B, Funari A, Michienzi S, Di Cesare S, Piersanti S, Saggio I, Tagliafico E, Ferrari S, Robey PG, Riminucci M, 
Bianco P (2007) Self-renewing osteoprogenitors in bone marrow sinusoids can organize a hematopoietic microenvironment. Cell 131:324

Seferos DS, Giljohann DA, Hill HD, Prigodich AE, Mirkin CA (2007) Nano-flares: probes for transfection and mRNA detection in living cells. J Am Chem Soc 129:15477

Seftor EA, Seftor REB, Weldon D, Kirsammer GT, Margaryan NV, Gilgur A, Hendrix MJC (2014) Melanoma tumor cell heterogeneity: a molecular approach to study subpopulations expressing the embryonic morphogen nodal. Semin Oncol 41:259

Sivasubramaniyan K, Harichandan A, Schumann S, Sobiesiak M, Lengerke C, Maurer A, Kalbacher H, Buhring HJ (2013) Prospective isolation of mesenchymal stem cells from human bone marrow using novel antibodies directed against Sushi domain containing 2. Stem Cells Dev 22:1944

Tian Y, Xu Y, Fu Q, Chang M, Wang Y, Shang X, Wan C, Marymont JV, Dong Y (2015) Notch inhibits chondrogenic differentiation of mesenchymal progenitor cells by targeting Twist1. Mol Cell Endocrinol 403:30

Yang J, Anholts J, Kolbe U, Stegehuis-Kamp JA, Claas FHJ, Eikmans M (2018) Calcium-binding proteins S100A8 and S100A9: investigation of their immune regulatory effect in myeloid cells. Int J Mol Sci 19:1833

Publisher's Note Springer Nature remains neutral with regard to jurisdictional claims in published maps and institutional affiliations. 